\title{
Barriers to infrastructure sustainability for mountainous townships in Chongqing
}

\author{
Yujuan She ${ }^{1,2, a}$, Hongfeng Liu ${ }^{1, b}$, Tianhong Jiang ${ }^{1, c}$
}

1 School of Civil Engineering and Architecture, Chongqing University of Science \& Technology, Chongqing, China

2 School of Construction Management and Real Estate, Chongqing University, Chongqing, China

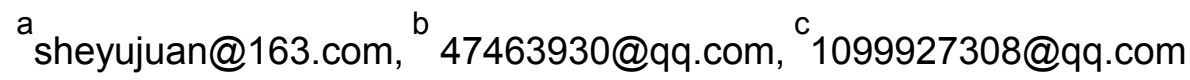

Keywords: Mountainous townships, Infrastructure sustainability, Barriers

Abstract: Chongqing is a typical mountainous city with a lot of less developed mountainous townships which are important components in the process of pursuing the mission of sustainable development in China. It is appreciated that the investment on infrastructure projects in these less developed townships is the key for driving their development. Nevertheless, their long-term sustainability performance is largely overlooked. It is considered essential to understand what restrain the sustainability performance of these infrastructures in order to take due actions for improving the performance. These barriers are identified in this study by using Semi-structured expert interview and Exploratory Factor Analysis (EFA) techniques. The study reveals that the major barriers include four dimensions.

\section{Introduction}

Chongqing, locating in West China, is one of four municipalities in China and a typical mountainous city with the mountainous area accounting for $70 \%$ of the land area. Mountainous regions have the typical characteristics of weak ecological carrying capacity, extremely sensitive and unstable ecological environment $[1,2]$. So the natural ecosystem in these regions is easy to be damaged for any carelessness during the construction and economic activity. According to the "21st century agenda" in 1992[3], the importance and fragility of mountainous ecosystem has been addressed, highlighting that sustainable development of mountainous regions is the major challenge faced by human kind. In mountainous regions, due to the barriers by difficult terrains, steep gradients, complex geological structure, climatic conditions and rich flora, it is considered not suitable for large-scale urban construction $[1,2]$. As a result, townships play more significant role in mountainous regions[4].

The development of mountainous townships relies largely on the improvement of infrastructure conditions $[5,6]$. However, it is appreciated that the sustainability performance of infrastructure is poor in Chinese townships especially in mountainous regions [7]. Liu et al. [8] suggested that mountainous townships usually have insufficient infrastructures, especially environmental infrastructure, and ineffective maintenance practice because of short-term behavior, which leads to typical problems such as short lifespan and serious environmental pollution. The obstacles to the sustainability of infrastructure in mountainous townships are numerous and the understanding on them is still limited.

Exiting research works in relation to this study can be examined from the following two perspectives, the sustainability of infrastructure and mountainous townships. Researchers present the connotation of infrastructure sustainability from different perspectives. In line with the principle 
of sustainable development, the infrastructure projects should be developed to bring benefits across economic aspect, social aspect, and environmental aspect $[5,6]$. In view of the lifespan, implementing "sustainable infrastructure" involves three life stages of project planning, project construction and operations [9].

Research works about mountainous regions and townships are across various dimensions. Kumar[1] pointed out that the construction regulations in mountainous regions should be made according to mountainous characteristics. The studies by other researchers investigate the effects of the geographic characteristics of mountainous regions on their economic development $[2,7,10]$. On the other hand, China's township serves as central places in rural China[4]. In study the townships in China, Gu et al. [4] pointed out that townships usually are weak in revenue making, lack of authority to self-govern and lack of economic activities. Liu et al.[7] indicated the shortage of infrastructures for the development of mountainous townships.

It can be seen from the previous researches that the principle of infrastructure sustainability has been well addressed, but the backgrounds of mountainous townships have not been incorporated. As a result, this paper aims to identify and analyze these barriers to the sustainability performance of infrastructure within the reference to mountainous townships in Chongqing, which is essential to help better decision-making for infrastructure development in the mountainous townships.

\section{Research methods}

\section{Semi-structured expert interview}

This paper starts with conducting literatures, official documents, and authoritative websites to help identify the candidate barriers affecting the sustainability of infrastructure projects in mountainous regions. Nevertheless, it appears that there are few literatures available on this subject. Therefore, semi-structured interviews are also adopted to identify the representative barriers. It is planned to select a group of experts who have knowledge of sustainability and the practice in developing infrastructure in townships.

\section{Questionnaire survey}

A questionnaire survey is conducted in this paper to collect the data in mountainous townships in Chongqing. The collected data is applied to analyze the classification of the barriers. The five-point Likert method is adopted to present respondents' view about the importance of each barrier, where 5 represents very important, and 1 represents negligible.

\section{Exploratory Factor Analysis}

Exploratory Factor Analysis (EFA) is a statistical technique for representing the relationships among many interrelated variables by a relatively small number of classification groups[11]. The EFA was undertaken in this study to identify the underlying relationships between the representative barriers and represent the classification of these representative barriers.

\section{Identification of barriers to infrastructure sustainability in mountainous townships}

\section{Candidate barriers from literature study}

Previous researches on the subjects of infrastructure sustainability and mountainous townships provide important reference to identify candidate barriers. The above literature studies lead to the production of a comprehensive list of candidate barriers, as listed in Table 1. 
Table 1 Candidate barriers to infrastructure sustainability in mountainous townships

\begin{tabular}{|c|c|c|}
\hline Code & Candidate barriers & $\begin{array}{l}\text { Literature } \\
\text { resources }\end{array}$ \\
\hline 1 & Influence from topography and landforms in mountainous regions & {$[1,2]$} \\
\hline 2 & More complex geologic structure in mountainous regions & {$[1,2]$} \\
\hline 3 & More ecological disasters in mountainous regions & {$[1,2]$} \\
\hline 4 & Higher request for environmental protect in mountainous regions & {$[1,3,7]$} \\
\hline 5 & Higher price of construction in mountainous regions & {$[1,12]$} \\
\hline 6 & Shortage of construction funds & {$[5,13]$} \\
\hline 7 & Public finance can't meet the need & {$[13]$} \\
\hline 8 & Limited access to financing & {$[5]$} \\
\hline 9 & Weak economic strength of township & {$[4,5]$} \\
\hline 10 & The economic downturn and town industrial recession & {$[14]$} \\
\hline 11 & Unattractiveness for investor to mountainous regions & {$[1]$} \\
\hline 12 & Lack of resources and development potential & [1] \\
\hline 13 & Unequal resources distribution between urban and townships & {$[5,8,14]$} \\
\hline 14 & Lack of authority to self-govern & {$[4]$} \\
\hline 15 & Fiscal mechanics of separation between revenue and expenditure & [4] \\
\hline 16 & Lack of laws and regulations for propelling infrastructure sustainability & {$[9,15]$} \\
\hline 17 & Lack of incentive mechanism & {$[16]$} \\
\hline 18 & Limited policy supports & {$[5,15]$} \\
\hline 19 & Insufficient public participation in policy-making & {$[17]$} \\
\hline 20 & Insufficient attention from superior administrative section & {$[8,12]$} \\
\hline 21 & Complicated administrative process & {$[5,12]$} \\
\hline 22 & Weak operability of administration means & {$[5,12]$} \\
\hline 23 & Government officials lack of knowledge of sustainable construction & {$[12]$} \\
\hline 24 & Inadequate management and maintain for infrastructure & {$[12,15]$} \\
\hline 25 & Workers poorly paid and trained leading to inefficient operation & {$[15]$} \\
\hline 26 & Obsolete technology of infrastructure construction in townships & [18] \\
\hline 27 & $\begin{array}{l}\text { Mismatch between supply and demand due to inadequate planning and analysis } \\
\text { in earlier stage }\end{array}$ & [8] \\
\hline 28 & Unreasonable Planning and redundant infrastructure & [8] \\
\hline 29 & $\begin{array}{l}\text { Without fully considering the special factors in mountainous environment when } \\
\text { planning }\end{array}$ & [1] \\
\hline 30 & Public lack of sustainability awareness & [1] \\
\hline 31 & Low level public education and low population quality & [15] \\
\hline
\end{tabular}

\section{Selection of the representative barriers}

In order to ensure that the barriers are adequately identified and representative, the suitability of the 31 candidate barriers identified in the above section will be examined through semi-structured interviews. The interviews involved 7 experts who have practical experience and or research experience in the field of construction and management in mountainous townships. Two of them work in construction administration department at county level in mountainous city (hereafter referred to county government), three work in mountainous township government, one is a consultant working in a consultant firm, and one is a senior researcher in the university.

Two rounds of interviews were conducted with each individual expert. In the first round interview, each expert was invited to present his or her view about the some structured questions in referring to the candidate list in Table 1. Based on their suggestions, a new list of candidate barriers was formulated. In the second round interview, the new list was presented to the experts for judgement. This has led to the output of 25 barriers as the final list, as shown in Table2. The selection of the representative barriers is based on the principle of "The minority gives way to the majority"[11]. In other words, a barrier in the candidate list is selected if four or more experts agree that such barrier is suitable and representative. 
Table 2 The selected representative barriers

\begin{tabular}{|c|c|c|c|c|c|c|c|c|}
\hline \multirow[t]{2}{*}{ Code } & \multirow[t]{2}{*}{ Representative barriers } & \multicolumn{7}{|c|}{$\begin{array}{c}\text { Experts' votes } \\
\text { (Y-accept N-reject) }\end{array}$} \\
\hline & & $\mathbf{A}$ & B & $\mathbf{C}$ & $\mathbf{D}$ & $\mathbf{E}$ & $\mathbf{F}$ & $\mathbf{G}$ \\
\hline B1 & More complex topography and landforms in mountainous regions & $\mathrm{N}$ & $\mathrm{Y}$ & $\mathrm{Y}$ & $\mathrm{Y}$ & $\mathrm{Y}$ & $\mathrm{Y}$ & $\mathrm{Y}$ \\
\hline B2 & More ecological disasters in mountainous regions & Y & $\mathrm{Y}$ & Y & Y & Y & $\mathrm{N}$ & Y \\
\hline B3 & Higher request for environmental protect in mountainous regions & $\mathrm{Y}$ & Y & Y & Y & Y & $\mathrm{Y}$ & $\mathrm{N}$ \\
\hline B4 & Higher price of construction in mountainous regions & $\mathrm{Y}$ & $\mathrm{Y}$ & $\mathrm{Y}$ & $\mathrm{Y}$ & $\mathrm{Y}$ & $\mathrm{Y}$ & Y \\
\hline B5 & Shortage of construction funds & $\mathrm{Y}$ & $\mathrm{Y}$ & $\mathrm{Y}$ & $\mathrm{Y}$ & $\mathrm{Y}$ & $\mathrm{Y}$ & Y \\
\hline B6 & Limited fiscal appropriation & $\mathrm{Y}$ & $\mathrm{Y}$ & $\mathrm{Y}$ & $\mathrm{Y}$ & $\mathrm{Y}$ & $\mathrm{Y}$ & $\mathrm{Y}$ \\
\hline B7 & Limited access to financing & $\mathrm{Y}$ & $\mathrm{Y}$ & $\mathrm{Y}$ & Y & Y & $\mathrm{Y}$ & Y \\
\hline B8 & Weak economic strength of township & $\mathrm{Y}$ & Y & $\mathrm{Y}$ & $\mathrm{Y}$ & $\mathrm{N}$ & $\mathrm{Y}$ & Y \\
\hline B9 & Unattractiveness for investor to mountainous regions & Y & Y & $\mathrm{Y}$ & Y & Y & $\mathrm{Y}$ & Y \\
\hline $\mathrm{B} 10$ & Lack of authority to self-govern & $\mathrm{Y}$ & $\mathrm{N}$ & $\mathrm{Y}$ & $\mathrm{Y}$ & $\mathrm{Y}$ & $\mathrm{N}$ & $\mathrm{N}$ \\
\hline $\mathrm{B} 11$ & Lack of laws and regulations for propelling infrastructure sustainability & $\mathrm{Y}$ & $\mathrm{N}$ & $\mathrm{N}$ & Y & Y & $\mathrm{Y}$ & Y \\
\hline $\mathrm{B} 12$ & Lack of incentive mechanism & $\mathrm{N}$ & $\mathrm{Y}$ & $\mathrm{Y}$ & $\mathrm{N}$ & $\mathrm{Y}$ & $\mathrm{Y}$ & Y \\
\hline B13 & Limited policy supports & $\mathrm{Y}$ & $\mathrm{Y}$ & $\mathrm{N}$ & $\mathrm{Y}$ & $\mathrm{Y}$ & $\mathrm{N}$ & $\mathrm{Y}$ \\
\hline B14 & Insufficient public participation in policy-making & $\mathrm{Y}$ & $\mathrm{Y}$ & $\mathrm{Y}$ & Y & $\mathrm{N}$ & $\mathrm{Y}$ & $\mathrm{Y}$ \\
\hline B15 & Insufficient attention from superior administrative section & $\mathrm{N}$ & $\mathrm{N}$ & $\mathrm{Y}$ & $\mathrm{N}$ & $\mathrm{Y}$ & $\mathrm{Y}$ & Y \\
\hline $\mathrm{B} 16$ & $\begin{array}{l}\text { Overlaps and unclearness of the responsibility between functional } \\
\text { departments }\end{array}$ & Y & $\mathrm{N}$ & Y & $\mathrm{Y}$ & $\mathrm{N}$ & $\mathrm{N}$ & Y \\
\hline $\mathrm{B} 17$ & Complicated administrative process & $\mathrm{N}$ & $\mathrm{Y}$ & $\mathrm{N}$ & $\mathrm{N}$ & $\mathrm{Y}$ & $\mathrm{Y}$ & Y \\
\hline $\mathrm{B} 18$ & Government officials lack of knowledge of sustainable construction & $\mathrm{Y}$ & $\mathrm{N}$ & $\mathrm{N}$ & $\mathrm{Y}$ & $\mathrm{N}$ & $\mathrm{Y}$ & $\mathrm{Y}$ \\
\hline B19 & Shortage of construction land index & $\mathrm{N}$ & $\mathrm{Y}$ & $\mathrm{Y}$ & $\mathrm{Y}$ & $\mathrm{Y}$ & $\mathrm{Y}$ & $\mathrm{N}$ \\
\hline $\mathrm{B} 20$ & Inadequate management and maintain for infrastructure & $\mathrm{N}$ & $\mathrm{Y}$ & $\mathrm{Y}$ & Y & $\mathrm{N}$ & $\mathrm{N}$ & Y \\
\hline $\mathrm{B} 21$ & $\begin{array}{l}\text { Mismatch between supply and demand due to inadequate planning and } \\
\text { analysis in earlier stage }\end{array}$ & $\mathrm{Y}$ & $\mathrm{N}$ & Y & $\mathrm{N}$ & $\mathrm{N}$ & $\mathrm{Y}$ & Y \\
\hline $\mathrm{B} 22$ & Redundant infrastructure & $\mathrm{N}$ & $\mathrm{Y}$ & $\mathrm{Y}$ & $\mathrm{N}$ & Y & $\mathrm{Y}$ & $\mathrm{N}$ \\
\hline $\mathrm{B} 23$ & Mismatch between the perspective map of township and the reality & $\mathrm{Y}$ & $\mathrm{N}$ & Y & $\mathrm{N}$ & Y & $\mathrm{Y}$ & Y \\
\hline $\mathrm{B} 24$ & Public lack of sustainability awareness & Y & $\mathrm{N}$ & Y & Y & $\mathrm{N}$ & $\mathrm{N}$ & Y \\
\hline $\mathrm{B} 25$ & Low population concentration & Y & Y & Y & $\mathrm{N}$ & Y & $\mathrm{N}$ & $\mathrm{N}$ \\
\hline
\end{tabular}

\section{Analysis on the representative barriers}

\section{Data collection}

The questionnaire survey is conducted to collect professionals' basic information and views on the measurements of significance of the 25 barriers. The questionnaire survey was conducted with the respondents covering 20 mountainous townships in Chongqing. Government officials in these townships and their corresponding superior government (county government) departments are selected as the main target respondents. There are other respondents coming from design organizations, construction enterprises, consultant firms and universities and they are approached through internet channel.

As a result, 160 questionnaires were distributed. As a result, 134 valid questionnaires were totally completed and returned, with a valid response rate of 84 percent.

\section{Classification of the barriers by using EPA method}

The collected data was analyzed with the Statistical Package for Social Science (SPSS 22.0). According to the result, the value of KMO equals to 0.865 , lager than 0.5 , which shows the 
collected data is appreciated for factor analysis. Meanwhile, the Bartlett test of Sphericity is 3915.971 and the associated significance level is 0.000 , less than 0.001 . It means that a few of common factors, reflecting the denominator of a group of variables, can be extracted.

In accordance with the evaluation criteria of eigenvalue $>1$, there are four common factors extracted from the 25 variables. The cumulative contribution of variance for the four factors accounted to $81.130 \%$. In other words, the four common factors can represent the majority of the 25 variables. In order to reflect the relation more obviously and explain the meaning of each common factor in practical words, orthogonal rotation in Varimax is needed for the original factor loading matrix. Then, after orthogonal rotation in Varimax with Kaiser Normalization [19], converged 6 iterations, there are four common factors covering the 25 variables, as shown in Table 3.

Table 3 Classification of Barriers

\begin{tabular}{cc}
\hline Common factors & Barriers \\
\hline F1 & B10,B11,B12,B13,B14, B19,B24,B25 \\
F2 & B15, B16, B17, B18, B20, B21, B22, B23 \\
F3 & B4,B5,B6,B7,B8, B9 \\
F4 & B1,B2,B3 \\
\hline
\end{tabular}

\section{Discussions}

After above procedures, the infrastructure sustainability in mountainous townships is affected by the barriers from four dimension.

In F1 dimension, there are 8 barriers as B10(Lack of authority to self-govern), B11(Lack of laws and regulations for propelling infrastructure sustainability),B12(Lack of incentive mechanism),B13(Limited policy supports),B14(Insufficient public participation in policy-making), B19(Shortage of construction land index), B24 (Public lack of sustainability awareness) and B25 (Low population concentration). Except B14 and B25the relating to public participation, the others involve policies instrument. In line with the practical connotation of each variable, this dimension is named as F1-Policy Instrument and Public Participation (PIPP).

In F2 dimension, there are also 8 barriers including B15(Insufficient attention from superior administrative section), B16 (Overlaps and unclearness of the responsibility between functional departments) , B17 (Complicated administrative process), B18 (Government officials lack of knowledge of sustainable construction ) , B20(Inadequate management and maintain for infrastructure), B21(Mismatch between supply and demand due to inadequate planning and analysis in earlier stage), B22(Redundant infrastructure) and B23(Mismatch between the perspective map of township and the reality). Thus, it can be seen that the major obstacles hindering infrastructure sustainability in this dimension mainly come from administrative efficiency. Therefore, this dimension is named as F2-Governance and Management (GM).

In F3 dimension, there are 6 barriers including B4(Higher price of construction in mountainous regions),B5(Shortage of construction funds),B6(Limited fiscal appropriation),B7(Limited access to financing),B8(Weak economic strength of township), and B9(Unattractiveness for investor to mountainous regions). Obviously, the barriers in this dimension involve cost, funds and economic strength. They all relate to economic issues. Therefore, this dimension is named as F3-Economic Capacity (EC).

In F4 dimension, there are 3 barriers including B1 (More complex topography and landforms in mountainous regions), B2 (More ecological disasters in mountainous regions) and B3 (Higher request for environmental protect in mountainous regions). In line with the practical connotation of the three barriers, the last dimension is named as F4- Local Geographic Characteristics (LGC). 


\section{Conclusions}

There are various barriers affecting sustainability performance of infrastructure, and this study has found 25 representative barriers. The analysis results through the above procedures demonstrate that the infrastructure sustainability in mountainous townships is affected by the barriers from four dimensions.

The findings on the barriers in this paper provide valuable reference for local governments in mountainous townships and upper-level decision-makers in Chongqing to take due actions for improving the sustainable performance of infrastructure. On the other hand, this study contributes to the development of literatures in the fields of infrastructure sustainability and townships development with particular reference to developing countries.

\section{Acknowledgments}

The authors would like to acknowledge the financial support for this research received from the Chongqing Municipal Education Committee (Grant No. KJ1713354).

\section{Reference}

[1] A. Kumar, Hbrc Journal 12 (2016) 316-326.

[2] J. Fan, Q. Wang, K. Zhou, D. Chen, City Planning Review (2013) 9-15.

[3] United Nations, Rio de Janeiro (1992).

[4] C. Gu, Y. Li, S.S. Han, Habitat International 50 (2015) 110-119.

[5] X. Zhang, Y. Wu, M. Skitmore, S. Jiang, Journal of Cleaner Production 107 (2015) 445-454.

[6] L. Shen, S. Jiang, H. Yuan, Habitat International 36 (2012) 237-246.

[7] C. Liu, J. Lei, H. Fu, Reform of Economic System (2006) 136-140.

[8] J. Liu, Y. Li, Urban Problems (2011) 61-66.

[9] S. Dasgupta, E.K.L. Tam, Canadian Journal of Civil Engineering 32 (2005) 30-44.

[10]C. Qin, J. Wang, Ecological Economy 10 (2012) 62-65.

[11]P. Kline, Routledge (1994).

[12]M. Chen, T. Liu, China Population, Resources and Environment (2004) 58-61.

[13]Z. Lu, F. Peña-Mora, X.R. Wang, C.Q. Shen, Z. Riaz, Procedia Engineering 123 (2015) 300-307.

[14] V. Visvaldis, G. Ainhoa, P. Ralfs, Procedia Computer Science 26 (2013) 21-32.

[15]C. Ezeah, C.L. Roberts, Journal of environmental management 103 (2012) 9-14.

[16]L. Shen, X. Song, Y. Wu, S. Liao, X. Zhang, Journal of Cleaner Production 127 (2016) 214-227.

[17]C.L. Choguill, Habitat International 20 (1996) 389-404.

[18]X. Wu, P. Cui, Sustainability 8 (2016) 1085.

[19]K. Law, Chongqing University press: Chongqing, China (2014). 